\title{
PERIGOS NATURAIS NA COMUNIDADE DO RIO CACHOEIRA, CAEIRA DO SACO DOS LIMÕES - FLORIANÓPOLIS/SC
}

\author{
Graziela Maziero Pinheiro Bini ${ }^{(a)}$, Edna Lindaura Luiz ${ }^{(b)}$ \\ (a) Doutoranda do Programa de Pós-Graduação em Geografia, Universidade de Santa Catarina (UFSC), \\ grazielabini@gmail.com \\ (b) Profa. Dra. do Departamento de Geografia, Universidade do Estado de Santa Catarina (UDESC), \\ elinluiz@uol.com.br
}

\section{Eixo: GEOGRAFIA FÍSICA E DESASTRES NATURAIS}

\begin{abstract}
Resumo
Este trabalho discute a suscetibilidade da bacia do rio Cachoeira a perigos do meio físico natural, bem como os acidentes relacionados a eles. Localizada no bairro Caeira do Saco dos Limões, Florianópolis/SC, a ocupação desta bacia ocorreu nos fundos de vales e nas encostas íngremes. Edificações próximas a cabeceiras de drenagem, canalização e desvio de rios, cortes em encostas e muros de contenção inapropriados são algumas das intervenções antrópicas encontradas na bacia, e que potencializam e criam perigos como: movimentos de massa, alagamentos, enxurradas, entre outros. O uso de material cartográfico detalhado, observações in loco, entrevistas e a experiência de vivência no local de uma das autoras deste trabalho subsidiaram a identificação dos perigos existentes na área de estudo. Diante do reconhecimento dos perigos naturais e dos elementos vulneráveis da bacia, trabalhos de prevenção, monitoramento e conscientização da comunidade devem ser realizados, a fim de evitar possíveis acidentes e desastres.
\end{abstract}

Palavras chave: Ocupação de encostas; Perigos naturais; Dinâmica do meio físico.

\section{Introdução}

A comunidade do rio Cachoeira faz parte do bairro Caieira do Saco dos Limões e está situada nas encostas do Maciço do Morro da Cruz, na região central de Florianópolis (Figura 1). Este ambiente de encosta limita e condiciona o processo de urbanização, pois os terrenos são inclinados, há presença de leitos de rios, afloramentos de blocos de rochas, solos rasos; além disso, também existe a manifestação da dinâmica natural, representada por processos como movimentos de massa, escoamento superficial, fluxos torrenciais em rios, especialmente em episódios de chuvas fortes e continuadas.

A população que habita a bacia é formada em sua maioria por imigrantes que chegaram na área há cerca de 45 anos, vindos de municípios como Tubarão, Braço do Norte, Alfredo Wagner (BINI, 2007). Já havia uma família habitando o baixo vale do rio Cachoeira, antes da chegada dos migrantes. Estes imigrantes não possuíam muitos recursos financeiros e por isso compraram os terrenos mais baratos que subiam as encostas da bacia, além disso, muitos deles não conheciam as particularidades e a dinâmica natural do lugar. 


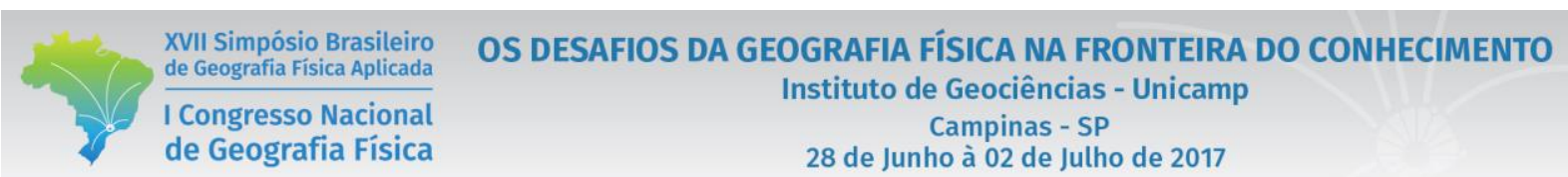

Sem capital para realizar modificações no relevo que levasse em consideração um conhecimento técnico acerca da bacia, muitos moradores fizeram pequenas alterações e obras de arte para tornar seus terrenos mais aptos em receber edificações. Desta forma, muitos cortes e aterros foram realizados, trechos de rios foram canalizados e ainda houve desvio de leito de rio.

Muitas intervenções antrópicas na bacia potencializaram ou desencadearam situações de perigo para os moradores. O perigo ou ameaça, segundo Palacios et al (2005), significa a probabilidade de ocorrência de um fenômeno natural ou induzido pelo homem capaz de provocar perdas e danos em elementos vulneráveis. A vulnerabilidade é definida pelos elementos que podem ser alvos de uma ameaça em potencial (VEYRET, 2007), ou seja, o quanto estes elementos podem ser afetados por uma determinada ameaça. O risco engloba a análise da ameaça e quanto de prováveis perdas e danos ela pode causar sobre os elementos vulneráveis. O objetivo do presente trabalho é apresentar os perigos naturais presentes na comunidade do rio Cachoeira, bairro Caieira- Florianópolis/SC e alguns de seus possíveis elementos vulneráveis.

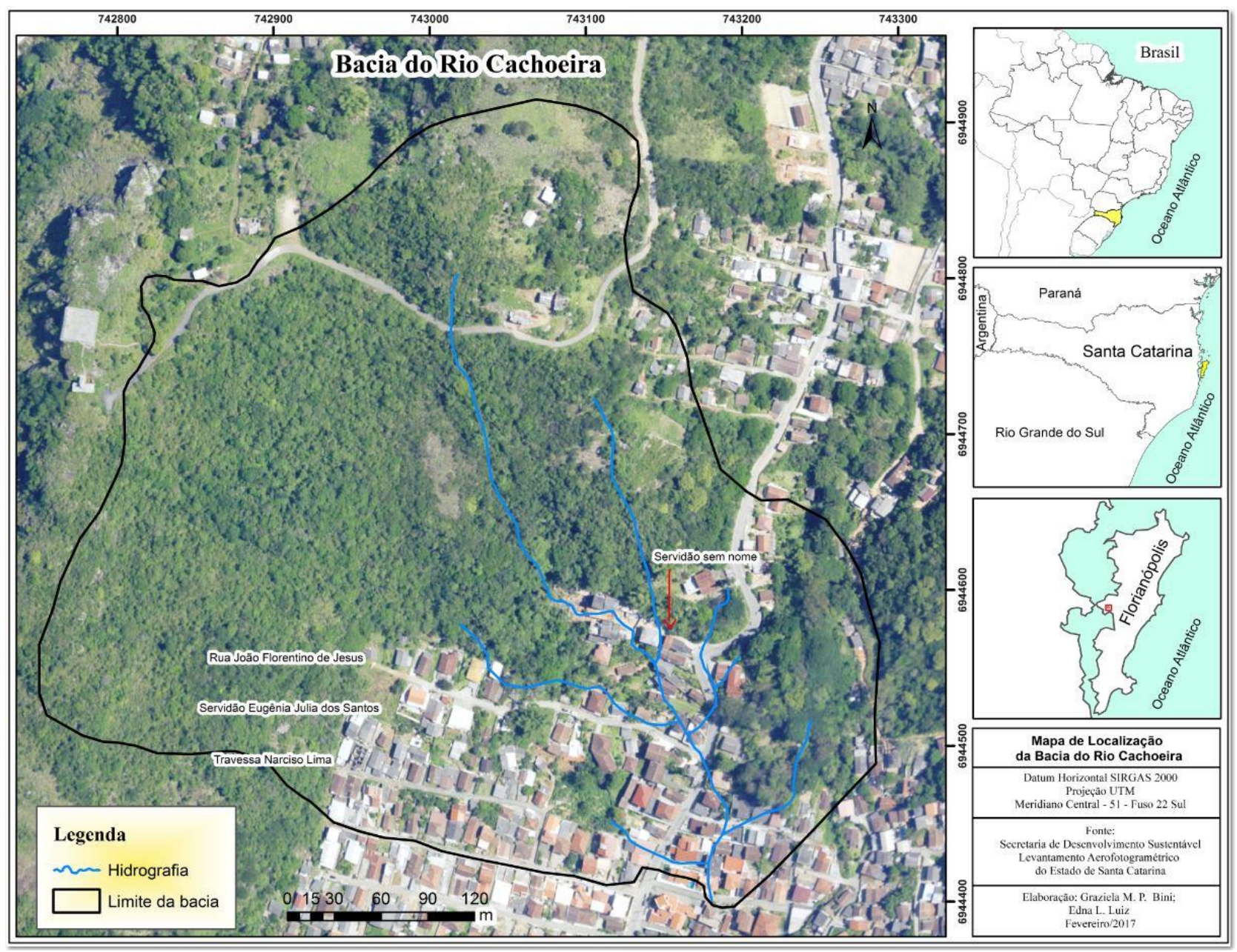

Figura 1- localização da área de estudo. 


\section{Materiais e métodos}

A identificação e a caracterização dos perigos constituídos pela dinâmica do meio físico da bacia do rio Cachoeira e dos elementos vulneráveis a eles (residências, arruamentos e outras estruturas) foram realizadas a partir de observações in loco ao longo dos arruamentos e propriedades, além de entrevistas informais com moradores do local e das experiências de vivência no local de uma das autoras do presente trabalho. Foi utilizada como planta-base para os trabalhos de campo, a folha SG-22-Z-D-V-Z-NE-F-I-6, cedida pelo Instituto de Planejamento Urbano de Florianópolis - IPUF, com curvas de nível com equidistância de $1 \mathrm{~m}$ e escala de 1:2.000.

\section{Resultados}

As situações de perigo encontradas na bacia do rio Cachoeira envolvem os processos morfogenéticos: movimento de massa, escoamento superficial concentrado, alagamento, inundação, assoreamento, erosão fluvial. Os elementos materiais vulneráveis mais comuns são as residências, mas há também problemas com pavimentação de ruas, rede pluvial, pequenas pontes construídas pelos próprios moradores. Os perigos observados efetivamente se manifestam durante chuvas intensas e/ou continuadas, como já ocorreu nos eventos de 1983, 1995, 2008 e 2011, os quais ainda estão muito presentes na memória da população do local. Alterações no substrato fisico da bacia realizadas pelos moradores se mostraram pontencialmente danosas. Os resultados serão apresentados de acordo com o tipo de perigo e por arruamento presente na bacia.

a) Uma residência localizada em uma encosta de um divisor secundário da bacia foi construída com cortes a montante e abaixo dela. O corte de montante apresenta muro de contenção sem saída para a água e ele foi usado como parede para um dos cômodos da residência. Este cômodo acaba não sendo utilizado em função da intensa umidade ali presente. O corte abaixo possui muro de contenção, o qual já apresenta rachaduras e embarrigamento.

b) A jusante da residência discutida anteriormente há um curso d'água que apresenta expressivo processo de erosão de margem, alargando o seu canal. Se esse processo continuar, ele ameaça à integridade de duas residências. Os moradores locais tentam controlar esta erosão colocando lixo e entulho nas margens e no interior do leito.

c) Os terrenos junto ao terço superior da rua João Florentino de Jesus são extremamente inclinados e os moradores realizaram cortes e aterros para poderem construir suas residências. Alguns destes cortes possuem muro de contenção, embora tenham sido executados sem uma análise técnica adequada. Segundo 
relato de moradores, pelo menos dois destes muros já caíram em episódios de chuvas intensas e precisaram ser reconstruídos.

d) No alto da Rua João Florentino de Jesus, três residências correm o perigo de alagamento pela chegada de escoamento superficial concentrado vindo das partes mais altas e íngremes da encosta do Maciço do Morro da Cruz. Este fenômeno leva água e sedimentos para dentro dos quintais destas casas. Há evidências de erosão por escoamento superficial na forma de rachaduras no piso de concreto do quintal de uma delas.

e) O trecho do rio Cachoeira que segue aproximadamente paralelo com a rua João Florentino na encosta foi desviado de seu leito normal por moradores, os quais construíram residências sobre o antigo curso do rio. Em função disso, estas residências sofrem com excesso de umidade em seu interior. Em episódios de chuvas mais intensas e/ou continuadas, uma destas residências tem surgência de água que chega a provocar alagamento. Provavelmente, isto é consequência de água que se acumula sobre o antigo leito. As outras residências próximas do leito atual do rio são inundadas e assoreadas pelo seu extravasamento.

f) Próximo de onde a rua João Florentino de Jesus corta um trecho canalizado de um afluente do rio Cachoeira, há uma residência edificada exatamente em cima dele. Esta situação cria o perigo de inundação e de assoreamento para a residência e seus moradores. Durante as chuvas excepcionais de dezembro de 1995, esta canalização não suportou a vazão maior e se rompeu, com o fluxo torrencial do rio, destruindo um muro de contenção construído entre a residência e a rua. A residência quase sofreu desabamento, além de ter sido atravessada pelo fluxo e ter sido assoreada por uma quantidade significativa de lama e areia.

g) No alto da servidão Eugênia Júlia dos Santos, o solo é muito raso (neossolo litólico) e com muitos afloramentos rochosos que logo ficam saturados com a infiltração das águas devido à sua pouca espessura. Essa característica ocasiona a formação rápida e abundante de escoamento superficial concentrado, trazendo perigo de formação de enxurradas e assoreamentos para duas residências que estão no percurso do fluxo. Além disso, neste local há também residências que podem ser atingidas por queda e rolamentos de blocos rochosos.

h) Nos arredores da ligação entre a Servidão Eugênia Julia dos Santos e a Travessa Narciso Lima há casas que podem sofrer deslizamento por estarem construídas sobre a margem do leito encaixado de um afluente do rio Cachoeira. No mesmo trecho deste afluente estão situadas residências construídas com pilares dentro do leito do rio. Em um próximo evento de chuvas excepcionais, o aumento da vazão pode destruir os pilares e fazer desmoronar estas casas. Além disso, nesse trecho, o afluente apresenta erosão na margem direita. Após a passagem por essas residências, o rio é canalizado com tubulação de apenas $1 \mathrm{~m}$ de diâmetro, o que representa pouca capacidade para as vazões maiores que podem ocorrer. 
i) Junto ao sopé da encosta do Maciço do Morro da Cruz, o rio Cachoeira e seus afluentes abrem uma planície onde estão várias residências. Estas residências sofrem com os perigos de inundação e assoreamento. Em eventos de precipitação excepcional os moradores reclamam da quantidade de "barro" que as águas trazem para suas residências. Nesta planície, ocorre o encontro dos afluentes principais do rio Cachoeira, sendo que logo após estas confluências, o rio Cachoeira é canalizado com tubulação de $60 \underline{\mathrm{cm}}$ de diâmetro até a praia, na Baía Sul. A canalização passa por debaixo de três residências. No evento de precipitação extrema de dezembro de 1995, esta canalização não suportou a vazão e rompeu o piso dentro e fora destas residências. A moradora de uma destas residências relata que, nesta ocasião, o fluxo tinha tanta energia que chegou a levar uma geladeira. Portanto, essas residências além do perigo de inundação e assoreamento, apresentam também o perigo de fluxo torrencial se houver rompimento de canalização.

\section{Conclusão}

Os moradores são responsáveis por algumas das situações de perigo encontradas na área de estudo. Suas intervenções no meio fisico da bacia visam aplainar a inclinação dos terrenos a partir de cortes ou de aterros, os quais são feitos sem critério técnico, e de modificações na rede de drenagem para ocupar seus leitos. As canalizações com tamponamentos de diferentes trechos de rios, além de servirem para ocupar melhor os terrenos, também são realizadas por causa de mau cheiro, uma vez que alguns moradores jogam esgotos nos rios.

É importante destacar que as conversas com os moradores mostraram que eles não têm consciência dos perigos que correm e de que, muitas vezes, são os responsáveis pelas perdas e danos que sofrem em momentos de precipitações intensas e/ou continuadas, pois modificaram o relevo e a drenagem. Contudo, eles têm a percepção de que as chuvas são as grandes deflagradoras destes acidentes. Existe, apesar de todos os problemas, entre os moradores um sentimento de apego ao lugar.

\section{Bibliografia}

BINI, G. M. P. Suscetibilidade a eventos perigosos do meio físico da bacia do rio Cachoeira, Caeira do Saco dos Limões, Florianópolis - SC. 2007.54 f. TCC (Graduação) - Curso de Geografia, Centro de Ciências da Educação, Universidade do Estado de Santa Catarina, Florianópolis, 2007.

PALACIOS, J. D.; CHUQUISENGO, O.; FERRADAS, P. Gestión de riesgo en los gobiernos locales. Lima: Soluciones Prácticas - ITDG, 2005.

VEYRET, I. Introdução. In. VEYRET, I. (org.). Os riscos: o homem como agressor e vítima do meio ambiente. São Paulo: editora Contexto, 2007. 